\title{
Brain-derived Neurotrophic Factor Is Associated with Cognitive Impairment in Elderly Korean Individuals
}

\author{
Sang Jun Lee ${ }^{1}$, Jun-Hyung Baek ${ }^{1}$, Young-Hoon Kim ${ }^{1,2}$ \\ 'Department of Psychiatry, Inje University Haeundae Paik Hospital, ${ }^{2}$ Paik Institute for Clinical Research, Inje University College of Medicine, \\ Busan, Korea
}

\begin{abstract}
Objective: Brain-derived neurotrophic factor (BDNF) is a neurotrophin that is widely expressed in the mammalian brain and acts to regulate neuronal survival and influence cognitive processes. The present study measured serum BDNF levels to investigate the associations of the BDNF Val66Met and 5-hydroxytryptamine transporter linked promoter region (5-HTTLPR) polymorphisms with cognitive function in elderly Korean individuals.

Methods: Over 60 years, a total of 834 subjects were recruited for the present study. The subjects were classified into groups based on the degree of cognitive impairment (age-associated cognitive decline, mild cognitive impairment, and Alzheimer's disease) and compared with normal controls in terms of a neuropsychological assessment and a clinical evaluation.

Results: Of the initial 834 study participants, 165 (59 controls and 106 subjects with cognitive impairments) completed the study. There was a significant increase in serum BDNF levels in subjects with cognitive impairments relative to the control group and the BDNF Val66Met polymorphism was significantly associated with cognitive function but not serum BDNF levels. The 5-HTTLPR polymorphism did not have any associations with cognitive impairment or serum BDNF levels.

Conclusion: The present findings suggest that BDNF may play a role in the pathophysiology of cognitive impairment and the BDNF Val66Met polymorphism may be an important factor in the susceptibility to these age-related deficits.
\end{abstract}

KEY WORDS: Brain-derived neurotrophic factor; Dementia; Cognition; Genetic polymorphism.

\section{INTRODUCTION}

The lifetime risk of Alzheimer's disease (AD) is 1 in $5^{1)}$ and the number of affected people is rising rapidly as life expectancy increases. ${ }^{2)}$ However, despite intensive study in recent years, there is still an incomplete understanding of the etiology and pathophysiology of this disease.

Brain-derived neurotrophic factor (BDNF) is one of a family of neurotrophins that plays an important role in the development, maintenance, and function of neurons. ${ }^{3)}$ BDNF is critical for neuronal plasticity and facilitates hippocampal and cortical long-term potentiation, ${ }^{4)}$ which are processes that are particularly important for learning and memory. These processes are substantially affected in patients with $\mathrm{AD}$, largely due to impaired neuronal plasticity. In $\mathrm{AD}$ patients, $\mathrm{BDNF}$ expression is prominently reduced

\footnotetext{
Received: November 12, 2014 / Revised: March 3, 2015

Accepted: June 22, 2015

Address for correspondence: Young-Hoon Kim, MD, PhD

Department of Psychiatry, Inje Univserity Haeundae Paik Hospital,

875 Haeun-daero, Haeundae-gu, Busan 48108, Korea

Tel: +82-51-797-1236, Fax: +82-51-894-6709

E-mail:npkyh@chol.com
}

in the hippocampus and the entorhinal cortex ${ }^{6}$ but there is conflicting evidence regarding the association between serum BDNF levels and the expression of AD. ${ }^{7-12)}$

A number of studies have identified genes that could be potential risk factors for $\mathrm{AD}$ but few of these findings have been replicated. Several studies have indicated that a single-nucleotide polymorphism (SNP) in the BDNF gene (dbSNP number rs6265) that results in a valine to methionine substitution at codon 66 (Val66Met) in the proBDNF sequence is associated with cognitive dysfunction and $\mathrm{AD} .^{13,14)}$ Similarly, a relationship between a functional polymorphism within the promoter region of the 5-HT transporter gene (5-HTTLPR) and the psychiatric symptoms of $\mathrm{AD}$ has also been demonstrated. ${ }^{15)}$

Thus, the present study investigated differences in serum BDNF levels and the distributions of the BDNF and 5-HTTLPR genotypes in subjects with cognitive impairment and a normal control group of elderly Korean people.

(a) This is an Open-Access article distributed under the terms of the Creative Commons Attribution Non-Commercial License (http://creativecommons.org/licenses/by-nc/4.0) which permits unrestricted non-commercial use, distribution, and reproduction in any medium, provided the original work is properly cited. 


\section{METHODS}

\section{Subjects}

The present study assessed 834 elderly individuals over 60 years of age. All subjects voluntarily participated in this study and written consent for all biological and genetic procedures was obtained. The study protocol was approved by the institutional review board of Busan Paik Hospital in Busan, South Korea. Subjects with psychotic features or depressive episodes based on the criteria of the Diagnostic and Statistical Manual of Mental Disorders, 4th edition (DSM-IV) and subjects with a history of organic brain abnormalities (e.g., vascular dementia, Parkinson's disease, etc) were excluded from the study.

\section{Assessment}

A screening test for dementia was performed on all subjects using the Korean version of the Mini-Mental Status Examination (MMSE-KC). Of the 626 subjects who had a score $>1.5$ standard deviations (SD) above the mean MMSE-KC score, 59 were randomly selected as the control group. Of the 208 subjects who had a score $>1.5 \mathrm{SD}$ below the mean MMSE-KC score, 106 agreed to undergo blood sampling and further examination. These additional assessments included the Consortium to Establish a Registry for AD, Korean version (CERAD-K), the Korean version of the Geriatric Depression Scale (K-GDS), the Hachinski Ischemic Scale, the Clinical Dementia Rating Scale (CDRS), and the DSM-IV diagnostic criteria.

The subjects were classified into cognitive impairment groups based on the results of their psychological tests and clinical evaluation: 26 subjects were classified with ageassociated cognitive decline (AACD), 55 subjects with mild cognitive impairment (MCI), and 25 subjects with $A D$.

\section{Biological Measurements}

Venous blood samples $(5 \mathrm{ml})$ from each subject were collected between 08:00 $\mathrm{h}$ and 10:00 h. Serum BDNF levels were measured using enzyme-linked immunosorbent assay (ELISA) kits (Promega, Maidison, WI, USA) and BDNF and 5-HTTLPR genotyping was performed.

\section{Statistical Analysis}

All analyses were conducted with PASW Statistics ver. 18.0 software for Windows (IBM Co., Armonk, NY, USA). An analysis of variance (ANOVA) was performed to assess the differences in clinical data among the groups and Student's $t$-tests were used to compare the serum BDNF concentrations of the subjects with cognitive impairments (AACD, MCI, and AD) with those of the control subjects. ANOVAs were used to assess differences in mean scores on the MMSE-KC and K-GDS and serum BDNF concentrations according to BDNF and 5-HTTLPR genotyping. Chi-square tests were performed to assess differences in the genotype and allelic frequencies between subjects with cognitive impairment and the control subjects. A $p$ value $<0.05$ was considered to indicate statistical significance.

\section{RESULTS}

Compared with the control group, subjects with cognitive impairment had higher K-GDS scores (Table 1) and increased serum BDNF concentrations $(26.8 \pm 5.3 \mathrm{ng} / \mathrm{ml}$ vs. $28.9 \pm 6.9 \mathrm{ng} / \mathrm{ml}, p<0.05$; Table 2). However, there were no significant differences in the mean scores on the MMSE-KC and K-GDS between the BDNF Val66Met and 5-HTTLPR genotypes or any significant associations of the BDNF Val66Met and 5-HTTLPR polymorphisms

Table 1. Clinical data of subjects

\begin{tabular}{|c|c|c|c|c|c|}
\hline & \multirow{2}{*}{$\begin{array}{c}\text { MMSE-KC < 1.5 SD } \\
\text { (normal cognition) }\end{array}$} & \multicolumn{3}{|c|}{$\begin{array}{l}\text { MMSE-KC } \geq 1.5 \text { SD } \\
\text { (impaired cognition) }\end{array}$} & \multirow[t]{2}{*}{$p$ value } \\
\hline & & AACD & $\mathrm{MCl}$ & $A D$ & \\
\hline CDR & 0 & 0 & 0.5 & $\geq 0.5$ & \\
\hline Subject (n) & 59 & 26 & 55 & 25 & \\
\hline Age $(y r)$ & $72.0 \pm 5.8$ & $70.8 \pm 4.4$ & $71.5 \pm 4.7$ & $73.3 \pm 6.8$ & 0.202 \\
\hline Education $(y r)^{*}$ & $6.3 \pm 4.3$ & $8.7 \pm 2.7$ & $6.6 \pm 4.3$ & $4.8 \pm 4.0$ & 0.001 \\
\hline MMSE-KC* & $24.7 \pm 3.7$ & $21.3 \pm 2.3$ & $19.5 \pm 3.4$ & $16.2 \pm 4.1$ & 0.001 \\
\hline K-GDS* & $12.0 \pm 6.7$ & $13.6 \pm 7.5$ & $16.4 \pm 7.2$ & $20.0 \pm 6.5$ & 0.000 \\
\hline Hachinski score* & - & $1.3 \pm 1.3$ & $1.4 \pm 1.5$ & $2.2 \pm 2.0$ & 0.016 \\
\hline
\end{tabular}

Values are presented as mean \pm standard deviation (SD).

MMSE-KC, Mini-Mental State Examination of Korean version; AACD, age associated cognitive decline; MCl, mild cognitive impairment; AD, Alzheimer's disease; CDR, Clinical Dementia Rating Scale; K-GDS, Korean version of Geriatric Depression Scale. ${ }^{*} p<0.05$. 
Table 2. The serum BDNF levels in the subjects with cognitive impairments and controls

\begin{tabular}{|c|c|c|c|c|c|c|}
\hline & \multirow{2}{*}{$\frac{\text { MMSE-KC }<1.5 \mathrm{SD}}{\text { Control }}$} & \multicolumn{4}{|c|}{ MMSE-KC $\geq 1.5$ SD } & \multirow{2}{*}{$p$ value } \\
\hline & & AACD & $\mathrm{MCl}$ & $A D$ & Total & \\
\hline BDNF concentration* & $26.8 \pm 5.3$ & $28.9 \pm 6.1$ & $28.7 \pm 7.0$ & $29.1 \pm 7.7$ & $28.9 \pm 6.9$ & 0.030 \\
\hline
\end{tabular}

Values are presented as mean \pm standard deviation (SD)

BDNF, brain-derived neurotropic factor; MMSE-KC, Mini-Mental State Examination of Korean version; AACD, age associated cognitive decline; $\mathrm{MCl}$, mild cognitive impairment; $\mathrm{AD}$, Alzheimer's disease; CDR, Clinical Dementia Rating Scale.

${ }^{*} p<0.05$ control versus total subjects with cognitive impairment.

Table 3. Genotypic differences in the mean scores of MMSE-KC and K-GDS, and the serum BDNF levels

\begin{tabular}{|c|c|c|c|c|c|c|c|c|}
\hline & \multicolumn{3}{|c|}{ BDNF Val66Met polymorphism } & \multirow{2}{*}{$p$ value } & \multicolumn{3}{|c|}{ 5-HTTLPR polymorphism } & \multirow{2}{*}{$p$ value } \\
\hline & V/V & $\mathrm{V} / \mathrm{M}$ & $\mathrm{M} / \mathrm{M}$ & & $s / s$ & $\mathrm{~s} / \mathrm{l}$ & $1 / 1$ & \\
\hline MMSE-KC & $22.0 \pm 4.7$ & $21.0 \pm 4.6$ & $20.7 \pm 4.5$ & 0.47 & $20.8 \pm 4.6$ & $21.3 \pm 4.8$ & $23.8 \pm 3.1$ & 0.11 \\
\hline K-GDS & $14.2 \pm 7.4$ & $14.5 \pm 7.5$ & $16.4 \pm 7.5$ & 0.37 & $15.0 \pm 7.0$ & $15.5 \pm 8.3$ & $10.6 \pm 5.8$ & 0.11 \\
\hline BDNF concentration & $27.4 \pm 7.8$ & $28.5 \pm 5.8$ & $27.9 \pm 6.6$ & 0.69 & $28.4 \pm 6.4$ & $28.1 \pm 6.9$ & $26.0 \pm 4,0$ & 0.50 \\
\hline
\end{tabular}

Values are presented as mean \pm standard deviation.

MMSE-KC, Mini-Mental State Examination of Korean version; K-GDS, Korean version of Geriatric Depression Scale; BDNF, brain-derived neurotropic factor; 5-HTTLPR, 5-hydroxytryptamine transporter-linked promotor region.

Table 4. Comparison of the genotype and allelic frequencies of BDNF Val66Met and 5-HTTLPR between groups

\begin{tabular}{|c|c|c|c|c|c|c|}
\hline & \multirow{2}{*}{$\frac{\text { MMSE-KC }<1.5 \mathrm{SD}}{\text { Control }}$} & \multicolumn{4}{|c|}{ MMSE-KC $\geq 1.5$ SD } & \multirow{2}{*}{$p$ value } \\
\hline & & AACD & $\mathrm{MCl}$ & $A D$ & Total & \\
\hline BDNF Val66Met genotype (\%) & & & & & & 0.032 \\
\hline V/V & 30.5 & 11.5 & 18.2 & 12.0 & 15.1 & \\
\hline $\mathrm{V} / \mathrm{M}$ & 54.2 & 57.7 & 56.4 & 60.0 & 57.5 & \\
\hline $\mathrm{M} / \mathrm{M}^{*}$ & 15.3 & 30.8 & 25.5 & 28.0 & 27.4 & \\
\hline Allele frequency (\%) & & & & & & 0.096 \\
\hline V Allele & 57.6 & 40.4 & 46.4 & 42.0 & 48.8 & \\
\hline M Allele & 42.4 & 59.6 & 53.6 & 58.0 & 51.2 & \\
\hline 5-HTTLPR genotype (\%) & & & & & & 0.648 \\
\hline$s / s$ & 50.8 & 53.8 & 61.8 & 64.0 & 57.0 & \\
\hline$s / l$ & 37.3 & 42.3 & 32.7 & 32.0 & 35.8 & \\
\hline $1 / 1$ & 11.9 & 3.8 & 5.5 & 4.0 & 7.3 & \\
\hline Allele frequency (\%) & & & & & & 0.369 \\
\hline s allele & 69.5 & 75.0 & 78.2 & 80.0 & 74.8 & \\
\hline I allele & 30.5 & 25.0 & 21.8 & 20.0 & 25.2 & \\
\hline
\end{tabular}

BDNF, brain-derived neurotropic factor; 5-HTLPR, 5-hydroxytryptamine transporter-linked promotor region; SD, standard deviation; MMSE-KC, Mini-Mental State Examination of Korean version; AACD, age associated cognitive decline; MCl, mild cognitive impairment; AD, Alzheimer's disease; CDR: Clinical Dementia Rating Scale.

$p$ value, control versus total subjects with cognitive impairment; * $p<0.05$.

with serum BDNF levels (Table 3).

The frequency of the BDNF Met/Met genotype was higher in subjects with cognitive impairment than in the controls (27.4\% vs. $15.3 \%, p<0.05$; Table 4 ) but no significant differences in BDNF allele distribution were found. The distributions of the 5-HTTLPR genotype and allele did not differ significantly between the two groups (Table 4).

\section{DISCUSSION}

\section{Serum BDNF Concentrations in the Subjects with Cognitive Impairment}

Recent findings have demonstrated that neurotrophic factors such as BDNF are associated with the pathophysiology of AD. BDNF is critical for the function and survival of neurons that degenerate in $\mathrm{AD}^{16)}$ and, thus, represents a potential neuroprotective agent that may be useful for the prevention of neurodegeneration; this has been clearly demonstrated in animal models. ${ }^{17,18)}$ Several studies have identified alterations in the serum BDNF levels of AD pa- 
tients but often with contrasting results. A majority of studies observed a decrease in serum BDNF levels ${ }^{7-11)}$ while fewer studies reported increased BDNF concentrations. ${ }^{12)}$

These discrepancies might be explained by differences in the severity of the cognitive impairments associated with the AD samples in different studies. Increased serum BDNF levels have been observed in patients with MCI and early $\mathrm{AD},{ }^{12,19)}$ which supports the notion that there is possibly a compensatory augmentation of neurotrophin synthesis in the earliest stages of AD progression. In line with these findings, the present study found increased serum BDNF levels in subjects with cognitive impairment. This may be due to the high proportion of subjects in the relatively early stages of cognitive impairment in the present sample.

\section{Associations of the BDNF Val66Met and 5-HTTLPR Polymorphisms with Cognitive Impairment}

Several recent studies investigated the association between the Val66Met allele of the BDNF gene and AD but the findings are ambiguous. While some studies found that this SNP was associated with $\mathrm{AD},{ }^{13,14)}$ others failed to find a significant association between the two. ${ }^{20-23)}$ Case-control studies addressing the association of 5-HTTLPR with AD have also produced conflicting results, but the majority were negative findings. $^{24-27)}$

In the present study, there were significant differences in the genotype distribution of the BDNF Val66Met polymorphism, but not the 5-HTTLPR polymorphism, between the cognitive impairment and normal control groups. The distribution of the BDNF Met/Met genotype was higher in subjects with cognitive impairment (AACD, MCI, and AD) compared to the controls $(p<0.05)$.

The BDNF Val66Met polymorphism affects the secretion of mature BDNF and has been implicated in the learning and memory processes of healthy humans. For example, carriage of the Met allele is associated with poor memory, reduced hippocampal volume, and lower hippocampal activation during functional imaging. ${ }^{28-30)}$ Crosssectional genetic association studies of subjects with AD have demonstrated that Met carriers exhibit greater impairments in memory and executive function, ${ }^{13)}$ a tendency for the earlier onset of $\mathrm{AD},{ }^{31)}$ reduced regional cerebral blood flow in the hippocampal and medial temporal lobe regions, ${ }^{32)}$ and reduced hippocampal and prefrontal cortical volumes. ${ }^{33)}$ However, other studies have observed greater levels of cognitive impairment, reduced brain structure volumes, and an increased risk of $\mathrm{AD}$ in subjects with the Val/Val genotype. ${ }^{34-36)}$ The absence of a clear re- lationship between the BDNF Val66Met allele and AD in previous studies could have been due to small sample sizes, different cross-sectional study designs, or the moderating influence of factors such as age and gender.

The present study has several limitations. Due to the cross-sectional design of the study, it is not clear whether the changes in BDNF levels preceded or followed the cognitive decline of the subjects. Additionally, it was not possible to adjust for potential confounding factors (e.g., age, sex, or smoking status) that could have influenced serum BDNF levels and the small sample size limits the generalizability of the present findings.

In summary, subjects with cognitive impairment (AACD, $\mathrm{MCI}$, and AD) had significantly higher serum BDNF levels than the normal control group in the present study. Furthermore, the BDNF Met/Met genotype was more frequently identified in subjects with cognitive impairment, which indicates that this allele might be associated with a susceptibility to cognitive impairment. These findings suggest that BDNF may be an important biological component underlying the pathophysiology of cognitive impairment and that the BDNF Val66Met polymorphism may be an important factor in the susceptibility to cognitive impairment.

\section{REFERENCES}

1. Seshadri S, Wolf PA. Lifetime risk of stroke and dementia: current concepts, and estimates from the Framingham Study. Lancet Neurol 2007;6:1106-1114.

2. Ferri CP, Prince M, Brayne C, Brodaty H, Fratiglioni L, Ganguli M, et al; Alzheimer's Disease International. Global prevalence of dementia: a Delphi consensus study. Lancet 2005;366:2112-2117.

3. Bramham CR, Messaoudi E. BDNF function in adult synaptic plasticity: the synaptic consolidation hypothesis. Prog Neurobiol 2005;76:99-125.

4. Figurov A, Pozzo-Miller LD, Olafsson P, Wang T, Lu B. Regulation of synaptic responses to high-frequency stimulation and LTP by neurotrophins in the hippocampus. Nature 1996;381:706-709.

5. Tapia-Arancibia L, Aliaga E, Silhol M, Arancibia S. New insights into brain BDNF function in normal aging and Alzheimer disease. Brain Res Rev 2008;59:201-220.

6. Holsinger RM, Schnarr J, Henry P, Castelo VT, Fahnestock M. Quantitation of BDNF mRNA in human parietal cortex by competitive reverse transcription-polymerase chain reaction: decreased levels in Alzheimer's disease. Brain Res Mol Brain Res 2000;76:347-354.

7. Yasutake C, Kuroda K, Yanagawa T, Okamura T, Yoneda H. Serum BDNF, TNF-alpha and IL-1beta levels in dementia patients: comparison between Alzheimer's disease and vascular dementia. Eur Arch Psychiatry Clin Neurosci 2006;256:402-406.

8. Laske C, Stransky E, Leyhe T, Eschweiler GW, Maetzler $\mathrm{W}$, Wittorf $\mathrm{A}$, et al. BDNF serum and CSF concentrations 
in Alzheimer's disease, normal pressure hydrocephalus and healthy controls. J Psychiatr Res 2007;41:387-394.

9. Yu H, Zhang Z, Shi Y, Bai F, Xie C, Qian Y, et al. Association study of the decreased serum BDNF concentrations in amnestic mild cognitive impairment and the Val66Met polymorphism in Chinese Han. J Clin Psychiatry 2008;69: 1104-1111.

10. Lee JG, Shin BS, You YS, Kim JE, Yoon SW, Jeon DW, et al. Decreased serum brain-derived neurotrophic factor levels in elderly Korean with dementia. Psychiatry Investig 2009;6:299-305.

11. Ventriglia M, Zanardini R, Bonomini C, Zanetti O, Volpe $\mathrm{D}$, Pasqualetti $\mathrm{P}$, et al. Serum brain-derived neurotrophic factor levels in different neurological diseases. Biomed Res Int 2013;2013:901082.

12. Angelucci F, Spalletta G, di Iulio F, Ciaramella A, Salani F, Colantoni L, et al. Alzheimer's disease (AD) and Mild Cognitive Impairment (MCI) patients are characterized by increased BDNF serum levels. Curr Alzheimer Res 2010;7: 15-20.

13. Ventriglia M, Bocchio Chiavetto L, Benussi L, Binetti G, Zanetti O, Riva MA, et al. Association between the BDNF 196 A/G polymorphism and sporadic Alzheimer's disease. Mol Psychiatry 2002;7:136-137.

14. Matsushita S, Arai H, Matsui T, Yuzuriha T, Urakami K, Masaki $\mathrm{T}$, et al. Brain-derived neurotrophic factor gene polymorphisms and Alzheimer's disease. J Neural Transm 2005;112:703-711.

15. Borroni B, Grassi M, Agosti C, Archetti S, Costanzi C, Cornali $\mathrm{C}$, et al. Cumulative effect of COMT and 5-HTTLPR polymorphisms and their interaction with disease severity and comorbidities on the risk of psychosis in Alzheimer disease. Am J Geriatr Psychiatry 2006;14:343-351.

16. Huang EJ, Reichardt LF. Neurotrophins: roles in neuronal development and function. Annu Rev Neurosci 2001;24:677736.

17. Pezet S, Malcangio M. Brain-derived neurotrophic factor as a drug target for CNS disorders. Expert Opin Ther Targets 2004;8:391-399.

18. Hennigan A, O'Callaghan RM, Kelly AM. Neurotrophins and their receptors: roles in plasticity, neurodegeneration and neuroprotection. Biochem Soc Trans 2007;35:424-427.

19. Laske C, Stransky E, Leyhe T, Eschweiler GW, Wittorf A, Richartz E, et al. Stage-dependent BDNF serum concentrations in Alzheimer's disease. J Neural Transm 2006;113:12171224.

20. Combarros O, Infante J, Llorca J, Berciano J. Polymorphism at codon 66 of the brain-derived neurotrophic factor gene is not associated with sporadic Alzheimer's disease. Dement Geriatr Cogn Disord 2004;18:55-58.

21. Bagnoli S, Nacmias B, Tedde A, Guarnieri BM, Cellini E, Petruzzi C, et al. Brain-derived neurotrophic factor genetic variants are not susceptibility factors to Alzheimer's disease in Italy. Ann Neurol 2004;55:447-448.

22. Desai P, Nebes R, DeKosky ST, Kamboh MI. Investigation of the effect of brain-derived neurotrophic factor (BDNF) polymorphisms on the risk of late-onset Alzheimer's disease $(A D)$ and quantitative measures of $A D$ progression. Neurosci Lett 2005;379:229-234.

23. He XM, Zhang ZX, Zhang JW, Zhou YT, Tang MN, Wu
$\mathrm{CB}$, et al. Lack of association between the BDNF gene Val66Met polymorphism and Alzheimer disease in a Chinese Han population. Neuropsychobiology 2007;55:151-155.

24. Fehér A, Juhász A, László A, Pákáski M, Kálmán J, Janka Z. Serotonin transporter and serotonin receptor $2 A$ gene polymorphisms in Alzheimer's disease. Neurosci Lett 2013;534:233-236.

25. Polito L, Prato F, Rodilossi S, Ateri E, Galimberti D, Scarpini E, et al. A novel study and meta-analysis of the genetic variation of the serotonin transporter promoter in the italian population do not support a large effect on Alzheimer's disease risk. Int J Alzheimers Dis 2011;2011: 312341.

26. Ueki A, Ueno H, Sato N, Shinjo H, Morita Y. Serotonin transporter gene polymorphism and BPSD in mild Alzheimer's disease. J Alzheimers Dis 2007;12:245-253.

27. Albani D, Prato F, Tettamanti M, Lovati C, Galimberti D, Restelli I, et al. The serotonin transporter promoter polymorphic region is not a risk factor for Alzheimer's disease related behavioral disturbances. J Alzheimers Dis 2009;18: 125-130.

28. Egan MF, Kojima M, Callicott JH, Goldberg TE, Kolachana BS, Bertolino A, et al. The BDNF val66met polymorphism affects activity-dependent secretion of BDNF and human memory and hippocampal function. Cell 2003;112:257-269.

29. Hariri AR, Goldberg TE, Mattay VS, Kolachana BS, Callicott JH, Egan MF, et al. Brain-derived neurotrophic factor val66met polymorphism affects human memoryrelated hippocampal activity and predicts memory performance. J Neurosci 2003;23:6690-6694.

30. Sambataro F, Murty VP, Lemaitre HS, Reed JD, Das S, Goldberg TE, et al. BDNF modulates normal human hippocampal ageing [corrected]. Mol Psychiatry 2010;15: 116-118.

31. Bicalho MA, Pimenta FA, Bastos-Rodrigues L, de Oliveira Hansen É, Neves SC, Melo M, et al. Sociodemographic characteristics, clinical factors, and genetic polymorphisms associated with Alzheimer's disease. Int J Geriatr Psychiatry 2013;28:640-646.

32. Xu C, Wang Z, Fan M, Liu B, Song M, Zhen X, et al; Alzheimer's Disease Neuroimaging Initiative. Effects of BDNF Val66Met polymorphism on brain metabolism in Alzheimer's disease. Neuroreport 2010;21:802-807.

33. Connor B, Young D, Yan Q, Faull RL, Synek B, Dragunow M. Brain-derived neurotrophic factor is reduced in Alzheimer's disease. Brain Res Mol Brain Res 1997;49:71-81.

34. Harris SE, Fox H, Wright AF, Hayward C, Starr JM, Whalley LJ, et al. The brain-derived neurotrophic factor Val66Met polymorphism is associated with age-related change in reasoning skills. Mol Psychiatry 2006;11:505-513.

35. Nagata T, Shinagawa S, Nukariya K, Yamada H, Nakayama K. Association between BDNF polymorphism (Val66Met) and executive function in patients with amnestic mild cognitive impairment or mild Alzheimer disease. Dement Geriatr Cogn Disord 2012;33:266-272.

36. Voineskos AN, Lerch JP, Felsky D, Shaikh S, Rajji TK, Miranda D, et al. The brain-derived neurotrophic factor Val66Met polymorphism and prediction of neural risk for Alzheimer disease. Arch Gen Psychiatry 2011;68:198-206. 